\title{
Neuro-Behçet's disease: A report of sixteen patients
}

This article was published in the following Dove Press journal:

Neuropsychiatric Disease and Treatment

2 May 2010

Number of times this article has been viewed

\section{Radi Shahien \\ Abdalla Bowirrat \\ Department of Neurology, Ziv \\ Medical Center, Safed, Israel}

Correspondence: Radi Shahien

Department of Neurology, Ziv Medical

Center, Zfat, I 3100 , Israel

$\mathrm{Tel}+$ I I $97246828927 / 8$

Fax + II 97246828648

Email shahien@ziv.health.gov.il
Background: Neurologic involvement in Behçet's disease (BD), also known as neuro-Behcet's disease (NBD), is one of the most devastating manifestations of the disease. The etiology of $\mathrm{BD}$ remains obscure and speculative. NBD usually occurs 1-10 years after the first symptom of $\mathrm{BD}$ has occurred, and its incidence is $18 \%$ (range of $4 \%-49 \%$ ).

Objective: This study was conducted to describe the clinical and prognostic aspects of neurologic involvement in $\mathrm{BD}$ among patients attending a multidisciplinary hospital clinic.

Methods: Eighty patients with BD were diagnosed according to the International Study Group Criteria for BD at our hospital. Sixteen patients (20\%, including 11 men and five women) had evidence of and fulfilled the diagnostic criteria for NBD. These patients underwent laboratory and imaging investigations, including human leukocyte antigen-typing, lumbar puncture, electroencephalographic studies, and computed tomography scanning.

Results: Fourteen of the 16 patients received high-dose steroids, and four of these 14 patients were treated with a combination of steroids and cytotoxic agents. Relief was observed in 14 of 16 patients $(87.5 \%)$. The remaining two patients were untreated males who suffered severe brainstem lesions, and later died.

Conclusion: In contrast with previous reports of a poor prognosis with NBD, our study shows that early aggressive intervention with corticosteroids and cytotoxic agents may ameliorate the prognosis in these patients, and can diminish and stabilize the negative effect of neurologic involvement.

Keywords: neuro-Behçet's disease, neurologic involvement, aphthous ulceration, genital ulceration, iridocyclitis

\section{Introduction}

In 1937, Hulusi Behçet, a Turkish dermatologist, described a "triple symptom complex" of aphthous ulceration, genital ulceration, and iridocyclitis ${ }^{1}$ (Figure 1). Since Behçet's original description, many musculoskeletal, gastrointestinal, urogenital, cardiac, cutaneous, and neurologic symptoms have been attributed to Behçet's disease (BD). ${ }^{2-4}$

Although the cause of BD is unknown, autoimmune, infectious, and genetic causes have been suspected. Environmental factors, such as microbial infections, are also suspected to be factors that contribute to the development of BD. Because BD has a characteristic geographic distribution spanning the Mediterranean basin and Asia, it is also known as "Silk Road" disease, ${ }^{5-6}$ the Silk Road being a geographic distribution along the historic route of commerce and travel between Europe and Asia. In fact, $\mathrm{BD}$ is more common (and often more severe) along the ancient Silk Road, especially 

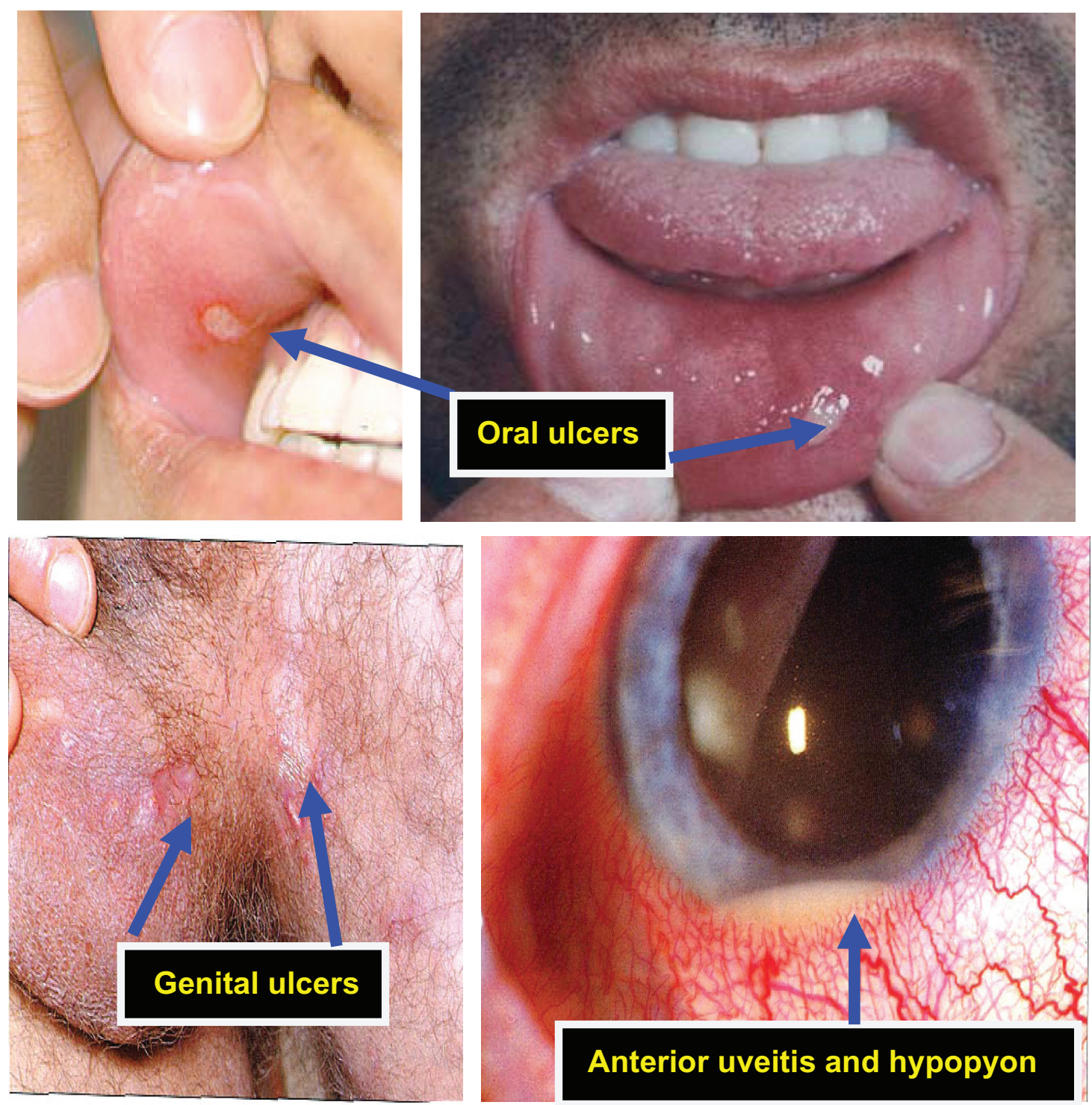

Figure I Triple symptom complex commonly observed in Behcet's disease: Aphthous ulceration, iridocyclitis, and genital ulceration. Aphthous ulceration often appears as the first symptom, ie, a painful, oval or round, shallow or deep, I-20 mm lesion with central whitish or yellowish necrotic base and red halo. Almost always present during flares, and may precede other features by years. Iridocyclitis and ocular disease is usually more bilateral than unilateral, with anterior uveitis and hypopyon commonly observed. Retinal involvement may also be present, ie, retinal vasculitis/optic neuritis or atrophy and genital ulceration, which are similar in appearance and usually present as large ulcers which are deep and often cause scarring.

from Eastern Asia to the Mediterranean. ${ }^{5}$ It is most common in Turkey $(80-300 / 100,000),{ }^{7}$ while the prevalence ranges from 10-20/100,000 in Japan, Korea, China, Iran, and Saudi Arabia. ${ }^{7-9}$ The prevalence of BD in Paris, France, in 2003 was reported to be 7.1/100,000, with rates of $2.4 / 100,000$ in those of European ancestry, 34.6 in those of North African ancestry, and 17.5 in those of Asian ancestry. ${ }^{10-11}$ The prevalence ranges from 1/15,000 to 1/500,000 in Northern American (Olmsted County, MN) and Northern European countries. ${ }^{5}$

BD is somewhat more common in men in the Eastern Mediterranean area and in women in Northern European countries, and typically affects young adults aged $20-40$ years. ${ }^{5}$
However, the epidemiology of the disease shows geographic variation, coupled with a similar variation in human leukocyte antigen (HLA)-B51 which has been reported to be associated strongly with the disease in high prevalence areas. ${ }^{12-15}$

Diagnosing BD can take a long time because symptoms may wax and wane, and it may take months or even years to develop all of the symptoms. There is no cure, and treatment focuses on reducing pain and preventing serious complications of the disease.

Currently, the most widely used diagnostic criteria for BD is the International Study Group's classification ${ }^{16}$ (Table 1), which requires recurrent oral ulceration plus two 
Table I International Study Group criteria for Behçet's disease ${ }^{16}$

\begin{tabular}{|c|c|}
\hline Recurrent oral ulcerations & $\begin{array}{l}\text { Minor aphthous, major aphthous, or herpetiform ulceration observed by physician } \\
\text { or patient, which recurred at least three times in one } 12 \text {-month period. }\end{array}$ \\
\hline \multicolumn{2}{|l|}{ Plus two of the following: } \\
\hline Recurrent genital ulceration & Aphthous ulceration or scarring observed by physician or patient. \\
\hline Eye lesion & $\begin{array}{l}\text { Anterior uveitis, posterior uveitis, or cells in vitreous on slit lamp examination } \\
\text { or retinal vasculitis observed by ophthalmologist. }\end{array}$ \\
\hline Skin lesion & $\begin{array}{l}\text { Erythema nodosum observed by physician or patient, pseudofolliculitis } \\
\text { or papulopastular lesions, or acneform nodules observed by physician in } \\
\text { postadolescent patients not on corticosteroid treatment. }\end{array}$ \\
\hline Positive pathergy test & Read by physician in $24-48$ hours. \\
\hline
\end{tabular}

of the following in order to establish a definite diagnosis, ie, recurrent genital ulcerations, skin or eye lesions, or a positive pathology test. ${ }^{17}$ Although the diagnosis is made on the basis of the combination of typical clinical symptoms, radiologic findings of $\mathrm{BD}$ show characteristic features of gastrointestinal, neurologic, cardiovascular, and thoracic organ system involvement. $^{2}$

In the gastrointestinal tract, $\mathrm{BD}$ may produce various types of ulcers in the esophagus, stomach, and small and large intestines, as well as deeply penetrating ulcerations in the ileocecal region, frequently accompanied by enteric fistulae. Neurologic involvement includes typical and atypical parenchymal NBD, dural sinus thrombosis, cerebral arterial aneurysm, occlusion, dissection, and meningitis. ${ }^{2}$

Neurologic involvement in BD was first reported in 1941 by Knapp, ${ }^{17}$ and the term "neuro-Behçet's syndrome" was introduced by Cavara and D'Ermo in 1954. ${ }^{18}$

The reported rate of development of neurologic involvement among BD patients ranges from $4 \%$ to $49 \% .{ }^{19-23}$ It has been reported that neurologic involvement develops over a time interval of more than 10 years after the onset of BD, ${ }^{22,24}$ and is classified as parenchymal or nonparenchymal. ${ }^{22,23}$

Parenchymal involvement primarily affects the brainstem, spinal cord, and cerebral hemispheres. Nonparenchymal involvement includes intracranial hypertension, aseptic meningitis, cranial neuropathy, and cerebrovascular disorders such as dural sinus thrombosis, arterial dissection, occlusion, and aneurysm. Central nervous system (CNS) involvement is one of the most dangerous manifestations of BD. ${ }^{20}$

The disease tends to involve the white matter portion of the brain and brainstem, and may lead to headaches, confusion, strokes, personality changes, and (rarely) dementia. BD may also involve the meninges, leading to meningitis. Because the meningitis of BD is not associated with any known infection, it is often referred to as "aseptic" meningitis. ${ }^{25} \mathrm{NBD}$ is commonly a motor-mental disorder, with a predilection for the brainstem and the basal ganglion region, as suggested by earlier neuropathology studies and neuroradiologic data. At the time of a neurologic attack, typical neuroradiologic findings have been defined. ${ }^{26}$

Polymorphonuclear pleocytosis and/or absence of IgG oligoclonal bands are suggestive of NBD. The presence of worse prognostic factors should be considered when treatment is initiated. The presence of abnormal cerebrospinal fluid (CSF) and parenchymal involvement, especially of the "brainstem +" type, justifies more aggressive treatment. ${ }^{22}$

Vascular involvement is divided into three subsets, including venous occlusion, arterial occlusion, and arterial aneurysm. ${ }^{3}$ Cardiac manifestations include intracardiac thrombus, endomyocardial fibrosis, periaortic pseudoaneurysm, and rupture of the sinus of Valsalva. ${ }^{2}$ Manifestations of BD in the thorax include pulmonary arterial aneurysm, pulmonary arterial thromboembolism, and thrombosis in the superior vena cava, pulmonary infarction, hemorrhage, and vasculitis of the pleura and pericardium. ${ }^{2,27}$

The various manifestations of $\mathrm{BD}$ respond to steroid treatment. ${ }^{28}$ However, one of the characteristics of BD is a high rate of complications and recurrence after surgery. Familiarity with its various radiologic and clinical characteristics is essential for making an accurate early diagnosis and for prompt treatment of patients with BD. Susceptibility to BD is strongly associated with the presence of the HLA-B51 allele, ${ }^{29-32}$ or HLA-B5, coupled by a negative lupus band test.

Although the pathogenesis of BD is largely unknown, associations with HLA-B51, genetic mutations including Factor $\mathrm{V}$ Leiden, and triggering by microbial antigens have been identified. ${ }^{33}$ Mutation of Factor V Leiden is recognized as the most common hereditary abnormality causing hypercoagulability, and is associated with BD.

NBD may present as acute focal or multifocal CNS dysfunction, and the clinical picture of NBD may resemble multiple sclerosis (MS). ${ }^{21,34-39}$

It has been observed that a substantial number of patients with NBD have a relapsing-remitting course while others 
may have a secondary progressive course. Some NBD patients have an insidious onset of the disease with primary progressive CNS dysfunction, and others may display symptoms attributable to intracranial hypertension associated with dural venous sinus thrombosis. ${ }^{40-42}$

Although nonneurologic involvement generally precedes neurologic findings, it may go unrecognized in some cases or may appear late in the course of $\mathrm{BD}$, thus posing diagnostic difficulties. ${ }^{43-45}$ Peripheral nerve involvement, although reported in NBD, is relatively uncommon. ${ }^{46}$

The purpose of this investigation was to determine the frequency of the various neurologic symptoms in $\mathrm{BD}$, to describe the clinical patterns of neurologic presentation in BD patients attending a multidisciplinary hospital clinic, and to examine the impact of neurologic disorders on the prognosis of the disease.

\section{Methods}

Eighty patients were identified as having been diagnosed with $\mathrm{BD}$ at our hospital during the previous 30 years. The diagnosis was based on at least three of four criteria, ie, aphthous stomatitis, genital ulceration, ophthalmic lesions, and skin erythema. Every patient suspected of suffering from neurologic symptoms was examined by a neurologist. The time interval elapsing between onset of the disease and appearance of neurologic symptoms was recorded.

The 80 patients were diagnosed according to the International Study Group's classification (Table 1), which requires recurrent oral ulcerations plus two of the following in order to establish a definite diagnosis, ie, recurrent genital ulcerations, skin or eye lesions, and supported by neutrophil chemotaxis, HLA-B51, or HLA-B5, and coupled with a negative lupus band test. Sixteen patients (20\%, including 11 men and five women) had evidence of NBD. Fifteen of these patients were of Middle Eastern or North African origin, and one patient was an Ashkenazi Jew. Age of onset in our series was 18-38 (mean age 25.5) years. Age of onset of neurologic symptoms was $25-41$ (mean 31.6) years. The time interval between onset of $\mathrm{BD}$ and neurologic manifestations varied widely, up to a maximum of 23 years. The 16 patients who had evidence of NBD underwent laboratory and imaging investigations. HLA-typing and electroencephalographic (EEG) studies were performed on all 16 patients, computed tomographic (CT) scan in 12, and lumbar puncture in 11 (Table 2).

\section{Results}

HLA-B51, which serves as an immunogenetic marker for a subgroup of patients with $\mathrm{BD}$, was present in nine NBD
Table 2 Results of laboratory investigations, EEG, CT scan, and CSF examination in 16 patients with $B D$

\begin{tabular}{lc}
\hline HLA-typing & \\
HLA-B5I & $9 / 16$ \\
HLA-B5 & $2 / 16$ \\
Others & $5 / 16$ \\
EEG & \\
Normal & $9 / 16$ \\
Diffuse slowing & $3 / 16$ \\
Diffuse slowing and sharp waves multispike and sharp wave & $2 / 16$ \\
Discharges (clinical convulsions) & $2 / 16$ \\
CT scan & \\
Normal & $9 / 16$ \\
Low density lesion in parietal lobe and in brainstem & $1 / 16$ \\
Low density lesion in brainstem & $1 / 16$ \\
Sagittal sinus thrombosis & $1 / 16$ \\
Not performed & $4 / 16$ \\
CSF & \\
Mainly lymphocytic pleocytosis & $11 / 16$ \\
Oligoclonal lgG-positive & $2 / 16$ \\
\hline
\end{tabular}

Abbreviations: CSF, cerebrospinal fluid; CT, computed tomography; EEG, electroencephalogram; HLA, human leukocyte antigen; IgG, immunoglobulin G.

patients, and HLA-B5 was present in two patients. EEG results were normal in nine patients, with three showing diffuse slowing, two showing diffuse slowing and sharp waves, and other two having clinical convulsions. CT scan was normal in nine patients, with one patient showing a low-density lesion in the parietal lobe and in the brainstem, one patient having a low-density lesion in the brainstem, and another patient show sagittal sinus thrombosis. The remaining four patients refused to undergo a CT scan. With regard to CSF results, 11 patients had predominantly lymphocytic pleocytosis and two patients had positive oligoclonal immunoglobulin $\mathrm{G}$ bands (Table 2). The most frequent neurologic manifestations were mild cognitive impairment (19\%), severe headache (12.5\%), convulsive disorders (12.5\%), dural sinus thrombosis (6\%), optic atrophy (19\%) and other cranial nerve palsies (19\%), hemispheric syndrome (19\%), severe brainstem lesions (12.5\%), pyramidal signs (19\%), cerebellar signs (19\%), myelopathy (20\%), and peripheral neuropathy $(6 \%$, Table 3$)$. Subacute onset and a relapsing-remitting course were the most commonly observed temporal patterns.

\section{Treatment}

Of 14 patients who received high-dose steroids, 13 were given prednisone $60-80 \mathrm{mg}$ /day orally and one patient was treated with intravenous methylprednisolone $1000 \mathrm{mg}$ /day, with gradual tapering of the dose. Four patients were treated with a combination of steroids and cytotoxic agents, namely 
Table 3 Neurological manifestations observed among our patients

Dural sinus thrombosis

Severe headache

Cognitive derangement

Optic atrophy

Other cranial nerve palsies

Hemispheric syndrome

Brainstem lesions

Pyramidal signs

Cerebellar signs

Myelopathy

Cauda equina syndrome

Peripheral neuropathy

Convulsions

azathioprine or chlorambucil. By the end of the treatment period, marked relief was observed in $87.5 \%$ of patients, except for two males who suffered severe brainstem lesions, did not receive any treatment, and subsequently died. One of these patients died three years after onset of severe neurologic symptoms, and the other died shortly after a brainstem stroke, having suffered from headache and a convulsive disorder for 30 years.

\section{Discussion}

Since the first description of BD in $1937,{ }^{17}$ and the subsequent first report of neurologic involvement in $\mathrm{BD}$ in $1941,{ }^{47}$ a plethora of studies of NBD have been reported. In addition to the triad of symptoms commonly observed in $\mathrm{BD}$, ie, aphthous ulceration, iridocyclitis, and genital ulceration, other multisystem disorders of unknown etiology have been reported, and almost all organ systems can be involved. ${ }^{2-4}$ Clinical involvement of the CNS is in the range $4 \%-49 \% .^{4,19-23,48}$

NBD can be mistaken for other CNS diseases with multifocal presentations, such as multiple sclerosis (MS) and systemic lupus erythematosus (SLE), especially in the absence of systemic manifestations of $\mathrm{BD} .^{22}$ In the acute phase of NBD, large confluent lesions in the brainstem-thalamic-basal ganglia region are highly suggestive of the disease, and can help to differentiate it from MS and SLE. ${ }^{26}$ In SLE, the lesions predominantly involve the subcortical white matter of the cerebral hemispheres and less frequently involve the basal ganglia or brainstem. ${ }^{26}$ In MS, the lesions are predominantly periventricular, with infrequent involvement of the basal ganglia and internal capsule. ${ }^{49}$ Moreover, brain stem lesions in MS are usually small, even in the acute stage, and seen along the floor of the fourth ventricle or anteriorly in the pons. This distribution contrasts with involvement of the central part of the pons in NBD. ${ }^{50}$ Spinal cord involvement in NBD tends to be extensive, whereas it rarely extends over more than two vertebral segments in MS. ${ }^{4}$

Neurologic involvement in BD is classified into parenchymal and nonparenchymal. ${ }^{22,23}$ Parenchymal NBD is more common, and presents with attacks of hemiparesis, cognitive changes, and sphincter disturbance. ${ }^{20}$ This form of involvement has a predilection for the brainstem, thalamic, and basal ganglia regions. The junction of the midbrain and thalamus (mesodiencephalic junction) is characteristically involved and it is the most common neural parenchymal structure involved. The pontobulbar region is the next most commonly affected area. ${ }^{51-54}$

The disease involves the basal ganglia and internal capsule region in one-third of the cases. The globus pallidus and posterior limb of the internal capsule are characteristically involved, and lesions in the basal ganglia may extend along the corticospinal tracts to the cervical cord. It should be noted that several factors influence the course and prognosis of NBD; parenchymal involvement, especially of the brainstem, and high CSF cellular and/or protein content, are significantly associated with a worse prognosis. ${ }^{51-54}$

Sixteen patients (11 males and 5 females) in this series had evidence of NBD (Tables 2 and 3). Two deaths occurred in patients who had suffered from severe brainstem lesions for a long time and had received no treatment during their illness. In the other 14 patients, brainstem lesions were absent, and other neurologic manifestations, including cognitive impairment, sphincter disturbance, and pyramidocerebellar involvement were relatively mild. In fact, mild cognitive impairment was observed in 3/16 patients (Mini-Mental state score 27, 28, and 29, possible total score 30).

Fourteen of the patients in this study improved or stabilized after aggressive steroid treatment, and a number had two or more episodes of neurologic involvement, with improvement on steroid therapy $(87.5 \%)$. In our view, their favorable prognosis was influenced by their stable clinical course and reduced disability. Certainly, early diagnosis and immediate administration of high-dose corticosteroid and cytotoxic therapy increased survival and decreased the disability and mortality in this patient series.

\section{Conclusion}

As described here, the clinical course of NBD may manifest in several ways, including a remittent form with a progressive trend, called the "remittent type", a remittent form that later becomes progressive, called the "remittent-progressive type", and the "progressive or monophasic type". 
The clinical course in our patients, except for the two deaths, was more benign, with two distinct patterns identified, ie, a monophasic or biphasic form with almost complete neurologic remission and a remittent or polyphasic form with no significant neurologic deficit between relapses.

Early administration of steroids, or combined steroid and cytotoxic therapy, may have beneficially influenced our findings. In contrast with previous reports of a poor prognosis in NBD, our study shows that immediate and aggressive treatment with corticosteroids and cytotoxic agents may ameliorate the prognosis in patients with mild to moderate NBD, and can diminish and stabilize the negative effect of neurologic involvement in the disease.

\section{Disclosures}

The authors report no conflict of interest in this work.

\section{References}

1. Behçet H. Uber rezidivierende Aphthose durch ein Virus-veursachtr Geschwur am Mund, am Auge und an den Genitalien. Dermatol Monatsschr. 1937;36:1152-1157.

2. Chae EJ, Kyung-Hyun D, Seo JB, et al. Radiologic and clinical findings of Behçet disease: Comprehensive review of multisystemic involvement. Radiographics. 2008;28:e31.

3. Kalko Y, Basaran M, Aydin U, Kafa U, Basaranoglu G, Yasar T. The surgical treatment of arterial aneurysms in Behçet disease: A report of 16 patients. J Vasc Surg. 2005;42:673-677.

4. Kocer N, Islak C, Siva A, et al. CNS involvement in neuro-Behcet syndrome: An MR study. Am J Neuroradiol. 1999;20:1015-1024.

5. Sakane T, Takeno M, Suzuki N, Inaba G. Behcet's disease. $N$ Engl J Med. 1999;341:1284.

6. James DG. Silk route disease. Postgrad Med J. 1986;62:151-153.

7. Yazici H, Yurdakul S, Hamuryudan V. Behcet's syndrome. In: Klippel JH, Dieppe PA, editors. Rheumatology. 2nd ed. London, UK: Mosby International; 1998.

8. Shimuzu T, Ehrlich GE, Inaba G, Hayashi K. Behcet disease (Behcet syndrome). Semin Arthritis Rheum. 1979;8:223-260.

9. Al-Dalaan A, Al-Balla S, Al-Sukait M, Bahabri S, Mousa M, Bigari T. The prevalence of Behcet's disease in Al Qassim region of Saudi Arabia. In: VIIth International Conference on Behcet's disease. Revue du Rhumatisme. English ed. 1996;63:539;Abstr C09.

10. Mahr A, Belarbi L, Wechsler B, et al. Population-based prevalence study of Behcet's disease: differences by ethnic origin and low variation by age at immigration. Arthritis Rheum. 2008;58:3951.

11. Yazici H, Seyahi E, Yurdakul S. Behcet's syndrome is not so rare: Why do we need to know? Arthritis Rheum. 2008;58:3640.

12. Yazici H, Akhan G, Yalçin B, Müftüolu A. The high prevalence of HLA-B5 in Behçet's disease. Clin Exp Immunol. 1977;30:259-261.

13. Yurdakul S, Günaydin I, Tüzün H, et al. The prevalence of Behçet's syndrome in a rural area in northern Turkey. J Rheumatol. 1988;15: 820-822.

14. Ohno S, Ohguchi M, Hirose S, Matsuda H, Wakisaka A, Aizava M. Close association of HLA-BW51 with Behçet's disease. Arch Opthalmol. 1982;100:1455-1458.

15. Mizuki N, Inoko H, Ohno S. Molecular genetics (HLA) of Behçet's disease. Yonsei Med J. 1997;38:423-427.

16. The International Study Group for Behçet's Disease. Evaluation of diagnostic ("classification") criteria in Behçet's disease: Towards internationally agreed criteria. Br J Rheumatol. 1992;31:299-308.
17. Knapp P. Beitrag zur Symptomatologie und Therapie der rezidiverenden Hypopyoniritis und der begleitenden apthösen Schleimhauterkrankungen. Shweiz Med Wochenschr. 1941;71:1288-1290.

18. Cavara V, D'Ermo E. A case of neuro-Behçet's syndrome. Acta XVII Concili Ophtalmologici. 1954;3:1489.

19. Serdaroglu P. Behçet's disease and the nervous system. J Neurol. 1998;245:197-205.

20. Farah S, Al-Shubaili A, Montaser A. Behçet's syndrome: A report of 41 patients with emphasis on neurological manifestations. J Neurol Neurosurg Psychiatry. 1998;64:382-384.

21. Siva A, Saip S, Kantarci O, et al. Neuro-Behçet syndrome (NBS): Clinical and imaging correlates. J Neurol. 1997;244 Suppl 3:545.

22. Akman-Demir G, Serdaroglu P, Tasci B. Clinical patterns of neurological involvement in Behçet's disease: Evaluation of 200 patients. The Neuro-Behçet Study Group. Brain. 1999;122:2171-2182.

23. Kidd D, Steuer A, Denman AM, Rudge P. Neurological complications in Behçet's syndrome. Brain. 1999;122:2183-2194.

24. Matsuo K, Yamada K, Nakajima K, Nakagawa M. Neuro-Behçet disease mimicking brain tumor. Am J Neuroradiol. 2005;26:650-653.

25. Kara B, Somer A, Pişkin S, Aydınlı N, Salman N, Yalçın I. Neuro-Behçet syndrome presenting as acute meningeal syndrome. J Infect. 2006;52:e120-e123.

26. Çoban O, Bahar S, Akman-Demir G, et al. Masked assessment of MRI findings: Is it possible to differentiate neuro-Behçet's disease from other central nervous system diseases? Neuroradiology. 1999;41:255-260.

27. Erkana F, Gülb A, Tasalia E. Pulmonary manifestations of Behçet's disease. Thorax. 2001;56:572-578.

28. Al-Fahad S, Al-Araji A. Neuro-Behçet's disease in Iraq: A study of 40 patients. J Neurol Sci. 1999;170:105-111.

29. Nabil Sakly N, Boumiza R, Zrour-Hassen S, et al. HLA-B27 and HLA-B51 determination in Tunisian healthy subjects and patients with suspected ankylosing spondylitis and Behçet's disease. Ann N Y Acad Sci. 2009;1173:564-569.

30. de Menthon M, LaValley MP, Maldini C, Guillevin L, Mahr A. HLAB51/B5 and the risk of Behçet's disease: A systematic review and meta-analysis of case-control genetic association studies. Arthritis Rheum. 2009;61:1287-1296.

31. Chang HK, Kim JU, Cheon KS, et al. HLA-B51 and its allelic types in association with Behçet's disease and recurrent aphthous stomatitis in Korea. Clin Exp Rheumatol. 2001;19(5 Suppl 24):S31-S35.

32. Mizuki N, Ota M, Katsuyama Y, et al. Sequencing-based typing of HLA-B*51 alleles and the significant association of HLA-B*5101 and -B*5108 with Behçet's disease in Greek patients. Tissue Antigens. 2002;59:118-121.

33. Verity DH, Wallace GR, Vaughan RW, Stanford MR. Behçet's disease: From Hippocrates to the third millennium. Br J Ophthalmol. 2003;87:1175-1183.

34. Morrisey SP, Miller DH, Hermaszewski R, et al. Magnetic resonance imaging of the central nervous system in Behçet's disease. Eur Neurol. 1993;33:287-293.

35. O'Duffy JD, Goldstein NP. Neurologic involvement in seven patients with Behçet's disease. Am J Med. 1976;61:170-178.

36. Motomura S, Tabira T, Koroiwa Y. A clinical comparative study of multiple sclerosis and neuro-Behçet's syndrome. J Neurol Neurosurg Psychiatry. 1980;43:210-213.

37. Herskovits S, Lipton R, Lantos G. Neuro-Behçet's disease: CT and clinical correlates. Neurology. 1988;38:1714-1720.

38. Miller DH, Ormerod IEC, Gibson A, DuBoulay EPGH, Rudge P, McDonald WI. MRI brain scanning in patients with vasculitis: Differentiation from multiple sclerosis. Neuroradiology. 1987;29:226-231.

39. Siva A, Saip S, Kantarci O, et al. Neuro-Behçet syndrome (NBS): Clinical and imaging features. Neurology. 1997;48 Suppl 1:Abstr 362.

40. Wechsler B, Vidailhet N, Piette JC, et al. Cerebral venous thrombosis in Behçet's disease: Clinical study and long-term follow-up of 25 cases. Neurology. 1992;42:614-618.

41. Saip S, Siva A, Basibüyük N, et al. Neuro-Behçet syndrome (NBS): Clinical and MRI features. Neurology. 1992;42 Suppl 3:Abstr 339. 
42. Harper CM, O’Neill BP, O’Duffy JD, Forbes GS. Intracranial hypertension in Behçet's disease: Demonstration of sinus occlusion with use of digital subtraction angiography. Mayo Clin Proc. 1985;60: 419-422.

43. Devlin T, Gray L, Allen NB, Friedman AH, Tien R, Morgenlander JC. Neuro-Behçet's disease: Factors hampering proper diagnosis. Neurology. 1995;45:1754-1757.

44. Kozin F, Haughton V, Bernhard GC. Neuro-Behçet disease: Two cases and neuroradiologic findings. Neurology. 1977;27:1148-1152.

45. Iragui VJ, Maravi E. Behçet syndrome presenting as cerebrovascular disease. J Neurol Neurosurg Psychiatry. 1986;49:838-840.

46. Baso P, Kara I, Eker E, et al. Clinical, electrophysiological, immunological and electron microscopic investigation of Behçet's disease. In: Dilsen N, Koniçe M, Ovul C, editors. Behçet's Disease. Amsterdam The Netharlands: Excerpta Medica International Congress Series; 1979.

47. Berlin C. Behçet's syndrome with involvement of central nervous system. Arch Dermatol Syph. 1944;49:227-233.

48. Guma A, Aguilera C, Acebes J, Arruga J, Pons L. Meningeal involvement in Behcet's disease: MRI. Neuroradiology. 1998;40:512-515.
49. Simon JH. Neuro-imaging of multiple sclerosis. Neuroimaging Clin $N$ Am. 1993;3:229-246.

50. Wechsler B, Dell'Isola B, Vidailhet M, et al. MRI in 31 patients with Behcet's disease and neurological involvement: Prospective study with clinical correlation. J Neurol Neurosurg Psychiatry. 1993;56: 793-798.

51. Al-Araji A, Kidd DP. Neuro-Behçet's disease: Epidemiology, clinical characteristics, and management. Lancet Neurol. 2009;8:192-204.

52. Siva A, Kantarci OH, Saip S, et al. Behçet's disease: Diagnostic and prognostic aspects of neurological involvement. J Neurol. 2001;248: 95-103.

53. Haghighi AB, Pourmand R, Nikseresht AR. Neuro-Behçet disease: A review. Neurologist. 2005;11:80-89.

54. Ho CL, Deruytter MJ. Manifestations of neuro-Behçet's disease: Report of two cases and review of the literature. Clin Neurol Neurosurg. $2005 ; 107: 310-314$.
Neuropsychiatric Disease and Treatment

\section{Publish your work in this journal}

Neuropsychiatric Disease and Treatment is an international, peerreviewed journal of clinical therapeutics and pharmacology focusing on concise rapid reporting of clinical or pre-clinical studies on a range of neuropsychiatric and neurological disorders. This journal is indexed on PubMed Central, the 'PsycINFO' database and CAS, and is the official

\section{Dovepress}

journal of The International Neuropsychiatric Association (INA). The manuscript management system is completely online and includes a very quick and fair peer-review system, which is all easy to use. Visit http://www.dovepress.com/testimonials.php to read real quotes from published authors.

Submit your manuscript here: http://www.dovepress.com/neuropsychiatric-disease-and-treatment-journal 